\title{
A Novel Modelling Approach of Modular Multi Three-phase Drive System for High Performance Applications
}

\author{
Xuchen Wang \\ Key Laboratory of More Electric Aircraft \\ Technology of Zhejiang Province \\ University of Nottingham Ningbo China \\ Ningbo, China \\ Xuchen.Wang@nottingham.edu.cn \\ He Zhang \\ Key Laboratory of More Electric Aircraft \\ Technology of Zhejiang Province \\ University of Nottingham Ningbo China \\ Ningbo, China \\ He.Zhang@nottingham.edu.cn
}

\author{
Chunyang $\mathrm{Gu}$ \\ Key Laboratory of More Electric Aircraft \\ Technology of Zhejiang Province \\ University of Nottingham Ningbo China \\ Ningbo, China \\ Chunyang.Gu@nottingham.edu.cn
}

Chris Gerada

Key Laboratory of More Electric Aircraft

Technology of Zhejiang Province

University of Nottingham Ningbo China

Ningbo, China

Chris.Gerada@nottingham.edu.cn

\author{
Giampaolo Buticchi \\ Key Laboratory of More Electric Aircraft \\ Technology of Zhejiang Province \\ University of Nottingham Ningbo China \\ Ningbo, China \\ Giampaolo Buticchi@nottingham.edu.cn
}

\begin{abstract}
There is a growing attention in the industrial and academic sectors for the multi-phase drive for high power and high-speed applications. The multi three-phase drive with independent neutral points is a popular option for this application, as it allows for the usage of standard control and standard power electronics for the individual three-phase systems. This work presents a novel model of multi three-phase drive. The mathematical modelling of multi three-phase permanent magnet synchronous machine (PMSM) and modular three-phase converters is presented. The electromagnetic torque equations of multi three-phase PMSM fed by modular converters are calculated. Finally, numerical results in a dual three-phase drive are presented to validate the analytical models.
\end{abstract} control

Keywords-Analytical models, multi three-phase drive, torque

\section{INTRODUCTION}

Multiphase drives have attracted an increasing attention for high speed and high power applications (e.g. aerospace applications) [1]-[3]. Among all multiphase drives, the multi three-phase drive (shown in Fig. 1) is one of the most popular option with its independent control of each three-phase subsystem [4]-[7]. In addition, commercial three-phase voltage source converters can be directly adopted to control the multi three-phase machines [8]-[10]. Therefore, modelling of multi three-phase drive systems is of high importance. Some research work has been done on the modelling of different drive systems [11]-[13]. This work is mainly focused on the mathematical modelling of multi threephase Permanent Magnet Synchronous Machines (PMSMs) fed by voltage source Pulse Width Modulation (PWM) converters.

In section II, a mathematical model of multi three-phase PMSM is presented by analyzing the relationship between phase voltages and phase currents through the PMSM stator winding inductance matrix. Section III illustrates the mathematical model of the PWM converters by using double Fourier integral analysis method. Section IV calculates the electromagnetic torque of multi three-phase drives. The

This work was supported by the Ningbo Science \& Technology Beauro under Grant 2017D10031, the China MoST project under Grant 2017YFB0102304, 2018B10001 and 2018B10002.

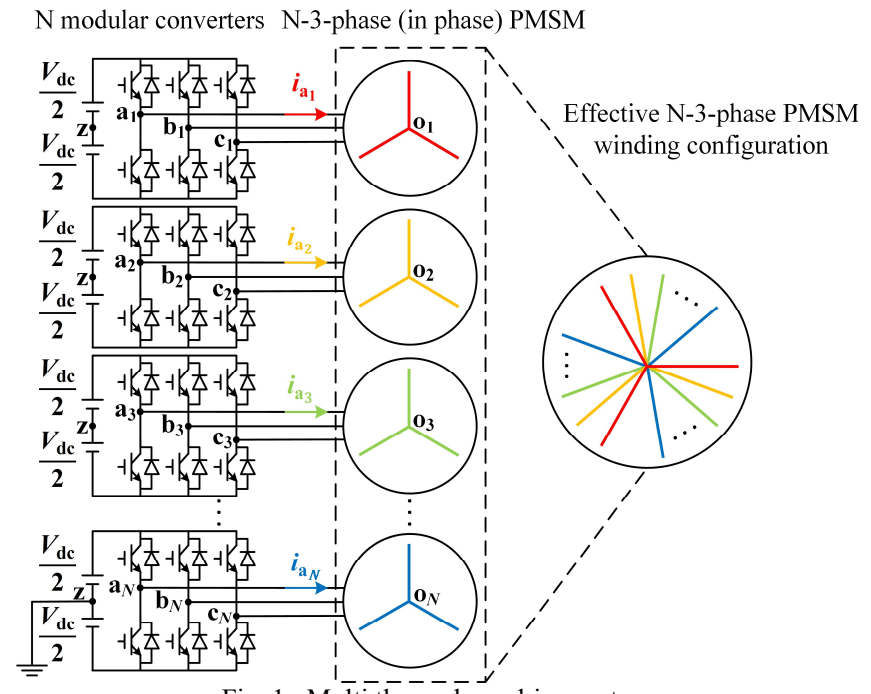

Fig. 1. Multi three-phase drive system

analytical models presented in Section II, III and IV are validated by numerical results in Section V. Finally, the conclusion of the paper is shown in Section VI.

\section{Mathematical Model of Multi Three-Phase PMSM}

The modelling of multi three-phase PMSM is based on the analysis of the relationship between phase voltages and currents. The inductance matrix, which establishes the relationship between phase currents and flux, allows for the calculation of the torque. While considering the selfinductance and mutual inductance of the inductance matrix of the PMSM, the effect of iron saturation is not considered, which means that the inductance value does not vary with the flux density. Assuming the self-inductance value on each stator phase $\mathrm{a}_{1}, \mathrm{~b}_{1}, \mathrm{c}_{1}, \ldots, \mathrm{a}_{N}, \mathrm{~b}_{N}, \mathrm{c}_{N}$ are represented by $\mathrm{L}_{\mathrm{a}_{1} \mathrm{a}_{1}}, L_{\mathrm{b}_{1} \mathrm{~b}_{1}}, L_{\mathrm{c}_{1} \mathrm{c}_{1}}, \ldots, L_{\mathrm{a}_{N} \mathrm{a}_{N}}, L_{\mathrm{b}_{N} \mathrm{~b}_{N}}, L_{\mathrm{c}_{N} \mathrm{c}_{N}}$ respectively. Assuming the mutual-inductance value between phase $\mathrm{a}_{1}$, $\mathrm{b}_{1}, \mathrm{c}_{1}, \ldots, \mathrm{a}_{N}, \mathrm{~b}_{N}, \mathrm{c}_{N}$ are represented by $M_{a_{1} \mathrm{~b}_{1}}, M_{\mathrm{a}_{1} \mathrm{c}_{1}}, \ldots$, $M_{\mathrm{c}_{N} a_{N}}, M_{\mathrm{c}_{N} b_{N}}$ respectively. The inductance matrix table is a $3 N \times 3 N$ matrix table, which can be represented by: 
$\boldsymbol{L}=\left[\begin{array}{ccccccc}L_{\mathrm{a}_{1} \mathrm{a}_{1}} & M_{\mathrm{a}_{1} \mathrm{~b}_{1}} & M_{\mathrm{a}_{1} \mathrm{c}_{1}} & & M_{\mathrm{a}_{1} \mathrm{a}_{N}} & M_{\mathrm{a}_{1} \mathrm{~b}_{N}} & M_{\mathrm{a}_{1} \mathrm{c}_{N}} \\ M_{\mathrm{b}_{1} \mathrm{a}_{1}} & L_{\mathrm{b}_{1} \mathrm{~b}_{1}} & M_{\mathrm{b}_{1} \mathrm{c}_{1}} & \cdots & M_{\mathrm{b}_{1} \mathrm{a}_{N}} & M_{\mathrm{b}_{1} \mathrm{~b}_{N}} & M_{\mathrm{b}_{1} \mathrm{c}_{N}} \\ M_{\mathrm{c}_{1} \mathrm{a}_{1}} & M_{\mathrm{c}_{1} \mathrm{~b}_{1}} & L_{\mathrm{c}_{1} \mathrm{c}_{1}} & & M_{\mathrm{c}_{1} \mathrm{a}_{N}} & M_{\mathrm{c}_{1} \mathrm{~b}_{N}} & M_{\mathrm{c}_{1} \mathrm{c}_{N}} \\ & \vdots & & \ddots & & \vdots & \\ M_{\mathrm{a}_{N} \mathrm{a}_{1}} & M_{\mathrm{a}_{N} \mathrm{~b}_{1}} & M_{\mathrm{a}_{N} \mathrm{c}_{1}} & & L_{\mathrm{a}_{N} \mathrm{a}_{N}} & M_{\mathrm{a}_{N} \mathrm{~b}_{N}} & M_{\mathrm{a}_{N} \mathrm{c}_{N}} \\ M_{\mathrm{b}_{N} \mathrm{a}_{1}} & M_{\mathrm{b}_{N} \mathrm{~b}_{1}} & M_{\mathrm{b}_{N} \mathrm{c}_{1}} & \cdots & M_{\mathrm{b}_{N} \mathrm{a}_{N}} & L_{\mathrm{b}_{N} \mathrm{~b}_{N}} & M_{\mathrm{b}_{N} \mathrm{c}_{N}} \\ M_{\mathrm{c}_{N} \mathrm{a}_{1}} & M_{\mathrm{c}_{N} \mathrm{~b}_{1}} & M_{\mathrm{c}_{N} \mathrm{c}_{1}} & & M_{\mathrm{c}_{N} \mathrm{a}_{N}} & M_{\mathrm{c}_{N} \mathrm{~b}_{N}} & L_{\mathrm{c}_{N} \mathrm{c}_{N}}\end{array}\right]$

Assuming $i$ and $j$ represent the $i^{\text {th }}$ row and the $j^{\text {th }}$ column of matrix $\boldsymbol{L}$ respectively. Due to the mutual inductance theory, $M_{i j}=M_{j i}$, so Matrix $\boldsymbol{L}$ is a real symmetric matrix. The Matrix $\boldsymbol{L}$ is strictly diagonally dominant matrix where $L_{i i}>$ $\sum_{j=1, j \neq i}^{3 N}\left|M_{i j}\right|$ and $L_{i i}>0$, Therefore, the inverse of matrix $\boldsymbol{L}$

$$
\left[\begin{array}{c}
u_{\mathrm{a}_{1}} \\
u_{\mathrm{b}_{1}} \\
u_{\mathrm{c}_{1}} \\
\vdots \\
u_{\mathrm{a}_{N}} \\
u_{\mathrm{b}_{N}} \\
u_{\mathrm{c}_{N}}
\end{array}\right]=\left[\begin{array}{ccccc}
L_{\mathrm{a}_{1} \mathrm{a}_{1}} & M_{\mathrm{a}_{1} \mathrm{~b}_{1}} & M_{\mathrm{a}_{1} \mathrm{c}_{1}} & & M_{\mathrm{a}_{1} \mathrm{a}_{N}} \\
M_{\mathrm{b}_{1} \mathrm{a}_{1}} & L_{\mathrm{b}_{1} \mathrm{~b}_{1}} & M_{\mathrm{b}_{1} \mathrm{c}_{1}} & \cdots & M_{\mathrm{b}_{1} \mathrm{a}_{N}} \\
M_{\mathrm{c}_{1} \mathrm{a}_{1}} & M_{\mathrm{c}_{1} \mathrm{~b}_{1}} & L_{\mathrm{c}_{1} \mathrm{c}_{1}} & & M_{\mathrm{c}_{1} \mathrm{a}_{N}} \\
& \vdots & & \ddots & \\
M_{\mathrm{a}_{N} \mathrm{a}_{1}} & M_{\mathrm{a}_{N} \mathrm{~b}_{1}} & M_{\mathrm{a}_{N} \mathrm{c}_{1}} & & L_{\mathrm{a}_{N} \mathrm{a}_{N}} \\
M_{\mathrm{b}_{N} \mathrm{a}_{1}} & M_{\mathrm{b}_{N} \mathrm{~b}_{1}} & M_{\mathrm{b}_{N} \mathrm{c}_{1}} & \cdots & M_{\mathrm{b}_{N} \mathrm{a}_{N}} \\
M_{\mathrm{c}_{N} \mathrm{a}_{1}} & M_{\mathrm{c}_{N} \mathrm{~b}_{1}} & M_{\mathrm{c}_{N} \mathrm{c}_{1}} & & M_{\mathrm{c}_{N} \mathrm{a}_{N}}
\end{array}\right.
$$

can be written as $\boldsymbol{L}^{-1}$, and the determinant of matrix $\boldsymbol{L}$ can be represented by $|\boldsymbol{L}|$, and $|\boldsymbol{L}|>0$ [14].

The phase voltage is voltage drop between terminals $a_{1}$, $\mathrm{b}_{1}, \mathrm{c}_{1}, \ldots, \mathrm{a}_{N}, \mathrm{~b}_{N}, \mathrm{c}_{N}$ and terminal $\mathrm{o}$, which can be represented by $u_{\mathrm{a}_{1}}, u_{\mathrm{b}_{1}}, u_{\mathrm{c}_{1}}, \ldots, u_{\mathrm{a}_{N}}, u_{\mathrm{b}_{N}}, u_{\mathrm{c}_{N}}$ respectively. The phase current is the current flowing through phase $a_{1}, b_{1}$, $\mathrm{c}_{1}, \ldots, \mathrm{a}_{N}, \mathrm{~b}_{N}, \mathrm{c}_{N}$, which can be represented by $i_{\mathrm{a}_{1}}, i_{\mathrm{b}_{1}}, i_{\mathrm{c}_{1}}$, $\ldots, i_{\mathrm{a}_{N}}, i_{\mathrm{b}_{N}}, i_{\mathrm{c}_{N}}$ respectively. The resistance of each phase is $R$. The back-EMF generated on each phase is represented by $e_{\mathrm{a}_{1}}, e_{\mathrm{b}_{1}}, e_{\mathrm{c}_{1}}, \ldots, e_{\mathrm{a}_{N}}, e_{\mathrm{b}_{N}}, e_{\mathrm{c}_{N}}$ respectively. According to the electric principle, the phase voltage equation can be represented by (1): simplified as:

$$
\boldsymbol{U}=\boldsymbol{L} \frac{\mathrm{d}}{\mathrm{d} t} \boldsymbol{I}+R \boldsymbol{I}+\boldsymbol{E}
$$

with:

$$
\boldsymbol{U}=\left[\begin{array}{c}
u_{\mathrm{a}_{1}} \\
u_{\mathrm{b}_{1}} \\
u_{\mathrm{c}_{1}} \\
\vdots \\
u_{\mathrm{a}_{N}} \\
u_{\mathrm{b}_{N}} \\
u_{\mathrm{c}_{N}}
\end{array}\right], \boldsymbol{I}=\left[\begin{array}{c}
i_{\mathrm{a}_{1}} \\
i_{\mathrm{b}_{1}} \\
i_{\mathrm{c}_{1}} \\
\vdots \\
i_{\mathrm{a}_{N}} \\
i_{\mathrm{b}_{N}} \\
i_{\mathrm{c}_{N}}
\end{array}\right], \boldsymbol{E}=\left[\begin{array}{c}
e_{\mathrm{a}_{1}} \\
e_{\mathrm{b}_{1}} \\
e_{\mathrm{c}_{1}} \\
\vdots \\
e_{\mathrm{a}_{N}} \\
e_{\mathrm{b}_{N}} \\
e_{\mathrm{c}_{N}}
\end{array}\right]
$$$$
\left[\begin{array}{l}
u_{\mathrm{a}, \mathrm{T}} \\
u_{\mathrm{b}, \mathrm{T}} \\
u_{\mathrm{c}, \mathrm{T}}
\end{array}\right]=\left[\begin{array}{lll}
L_{\mathrm{aa}, \mathrm{T}} & M_{\mathrm{ab}, \mathrm{T}} & M_{\mathrm{ac}, \mathrm{T}} \\
M_{\mathrm{ba}, \mathrm{T}} & L_{\mathrm{bb}, \mathrm{T}} & M_{\mathrm{bc}, \mathrm{T}} \\
M_{\mathrm{ca}, \mathrm{T}} & M_{\mathrm{cb}, \mathrm{T}} & L_{\mathrm{cc}, \mathrm{T}}
\end{array}\right] \frac{d}{d t}\left[\begin{array}{c}
i_{\mathrm{a}, \mathrm{T}} \\
i_{\mathrm{b}, \mathrm{T}} \\
i_{\mathrm{c}, \mathrm{T}}
\end{array}\right]+R\left[\begin{array}{c}
i_{\mathrm{a}, \mathrm{T}} \\
i_{\mathrm{b}, \mathrm{T}} \\
i_{\mathrm{c}, \mathrm{T}}
\end{array}\right]+\left[\begin{array}{c}
e_{\mathrm{a}, \mathrm{T}} \\
e_{\mathrm{b}, \mathrm{T}} \\
e_{\mathrm{c}, \mathrm{T}}
\end{array}\right],
$$

$$
\left.\begin{array}{c}
M_{\mathrm{a}_{1} \mathrm{c}_{N}} \\
M_{\mathrm{b}_{1} \mathrm{c}_{N}} \\
M_{\mathrm{c}_{1} \mathrm{c}_{N}} \\
M_{\mathrm{a}_{N} \mathrm{c}_{N}} \\
M_{\mathrm{b}_{N} \mathrm{c}_{N}} \\
L_{\mathrm{c}_{N} \mathrm{c}_{N}}
\end{array}\right] \frac{\mathrm{d} t}{\mathrm{~d} t}\left[\begin{array}{c}
i_{\mathrm{a}_{1}} \\
i_{\mathrm{b}_{1}} \\
i_{\mathrm{c}_{1}} \\
\vdots \\
i_{\mathrm{a}_{N}} \\
i_{\mathrm{b}_{N}} \\
i_{\mathrm{c}_{N}}
\end{array}\right]+R\left[\begin{array}{c}
i_{\mathrm{a}_{1}} \\
i_{\mathrm{b}_{1}} \\
i_{\mathrm{c}_{1}} \\
\vdots \\
i_{\mathrm{a}_{N}} \\
i_{\mathrm{b}_{N}} \\
i_{\mathrm{c}_{N}}
\end{array}\right]+\left[\begin{array}{c}
e_{\mathrm{a}_{1}} \\
e_{\mathrm{b}_{1}} \\
e_{\mathrm{c}_{1}} \\
\vdots \\
e_{\mathrm{a}_{N}} \\
e_{\mathrm{b}_{N}} \\
e_{\mathrm{c}_{N}}
\end{array}\right]
$$

Due to the symmetrical design principle of machine winding configurations, the inductance matrix table among multi three-phase systems $\mathrm{a}_{1}, \mathrm{~b}_{1}, \mathrm{c}_{1}, \ldots, \mathrm{a}_{N}, \mathrm{~b}_{N}, \mathrm{c}_{N}$ are identical, which means the inductance matrix $\boldsymbol{L}_{p p}=\boldsymbol{L}_{N N}, \boldsymbol{M}_{p q}=$ $\boldsymbol{M}_{p+1, q+1}, \quad \boldsymbol{M}_{N, q}=\boldsymbol{M}_{1, q+1} \quad, \quad$ where $\quad p \neq q, p, q \in$ $\{1,2, \ldots, N\}$, and:

$$
\begin{gathered}
\boldsymbol{L}_{p p}=\left[\begin{array}{lll}
L_{\mathrm{a}_{p} \mathrm{a}_{p}} & M_{\mathrm{a}_{p} \mathrm{~b}_{p}} & M_{\mathrm{a}_{p} \mathrm{c}_{p}} \\
M_{\mathrm{b}_{p} \mathrm{a}_{p}} & L_{\mathrm{b}_{p} \mathrm{~b}_{p}} & M_{\mathrm{b}_{p} \mathrm{c}_{p}} \\
M_{\mathrm{c}_{p} \mathrm{a}_{p}} & M_{\mathrm{c}_{p} \mathrm{~b}_{p}} & L_{\mathrm{c}_{p} \mathrm{c}_{p}}
\end{array}\right], \\
\boldsymbol{M}_{p q}=\left[\begin{array}{lll}
M_{\mathrm{a}_{p} \mathrm{a}_{q}} & M_{\mathrm{a}_{p} \mathrm{~b}_{q}} & M_{\mathrm{a}_{p} \mathrm{c}_{q}} \\
M_{\mathrm{b}_{p} \mathrm{a}_{q}} & M_{\mathrm{b}_{p} \mathrm{~b}_{q}} & M_{\mathrm{b}_{p} \mathrm{c}_{q}} \\
M_{\mathrm{c}_{p} \mathrm{a}_{q}} & M_{\mathrm{c}_{p} \mathrm{~b}_{q}} & M_{\mathrm{c}_{p} \mathrm{c}_{q}}
\end{array}\right] .
\end{gathered}
$$

Additionally, there is no phase displacements among different three-phase subsystems. Therefore, the back-EMFs generated on each phase are identical with the same magnitudes and phases, which means the back-EMF matrixes $\boldsymbol{E}_{p}=\boldsymbol{E}_{\mathrm{N}}$, where $p \in\{1,2, \ldots, N\}$, and:

$$
\boldsymbol{E}_{p}=\left[\begin{array}{l}
e_{\mathrm{a}_{p}} \\
e_{\mathrm{b}_{p}} \\
e_{\mathrm{c}_{p}}
\end{array}\right], \boldsymbol{E}_{N}=\left[\begin{array}{l}
e_{\mathrm{a}_{N}} \\
e_{\mathrm{b}_{N}} \\
e_{\mathrm{c}_{N}}
\end{array}\right] .
$$

According to operational properties of matrices, (1) can be rewritten as: simplified as:

$$
\boldsymbol{U}_{\mathrm{T}}=\boldsymbol{L}_{\mathrm{T}} \frac{d \boldsymbol{I}_{\boldsymbol{T}}}{d t}+R \boldsymbol{I}_{\mathrm{T}}+\boldsymbol{E}_{\mathrm{T}}
$$

with:

$$
\begin{gathered}
\boldsymbol{U}_{\mathrm{T}}=\left[\begin{array}{l}
u_{\mathrm{a}, \mathrm{T}} \\
u_{\mathrm{b}, \mathrm{T}} \\
u_{\mathrm{c}, \mathrm{T}}
\end{array}\right], \boldsymbol{L}_{\mathrm{T}}=\left[\begin{array}{lll}
L_{\mathrm{aa}, \mathrm{T}} & M_{\mathrm{ab}, \mathrm{T}} & M_{\mathrm{ac}, \mathrm{T}} \\
M_{\mathrm{ba}, \mathrm{T}} & L_{\mathrm{bb}, \mathrm{T}} & M_{\mathrm{bc}, \mathrm{T}} \\
M_{\mathrm{ca}, \mathrm{T}} & M_{\mathrm{cb}, \mathrm{T}} & L_{\mathrm{cc}, \mathrm{T}}
\end{array}\right], \\
\boldsymbol{I}_{\mathrm{T}}=\left[\begin{array}{l}
i_{\mathrm{a}, \mathrm{T}} \\
i_{\mathrm{b}, \mathrm{T}} \\
i_{\mathrm{c}, \mathrm{T}}
\end{array}\right], \boldsymbol{E}_{\mathrm{T}}=\left[\begin{array}{l}
e_{\mathrm{a}, \mathrm{T}} \\
e_{\mathrm{b}, \mathrm{T}} \\
e_{\mathrm{c}, \mathrm{T}}
\end{array}\right] .
\end{gathered}
$$

where $\boldsymbol{U}_{\mathrm{T}}$ is the total equivalent voltage; $\boldsymbol{I}_{\mathrm{T}}$ is the total equivalent current; $\boldsymbol{E}_{\mathrm{T}}$ is the total equivalent back-emf; $\boldsymbol{L}_{\mathrm{T}}$ is the total equivalent inductance.

According to (4), by using Laplace formula, neglecting the initial conditions, $\boldsymbol{U}_{\mathrm{T}}$ can be represented as:

$$
\boldsymbol{U}_{\mathrm{T}}=\left(s \boldsymbol{L}_{\mathrm{T}}+R\right) \boldsymbol{I}_{\mathrm{T}}+\boldsymbol{E}_{\mathrm{T}} \text {. }
$$

Neglecting the harmonics caused by cogging effect and the shape permanent magnet, the back-EMF is considered to be ideal sinusoidal. Therefore, for $\boldsymbol{U}_{\mathrm{T}}$ and $\boldsymbol{I}_{\mathrm{T}}$, only the fundamental component ${ }_{-}$and the harmonic components, which are generated by PWM modulation effect ${ }_{2}$ are considered-. According to (5), the total equivalent fundamental voltage $\boldsymbol{U}_{\mathrm{f}}$, the total equivalent fundamental current $\boldsymbol{I}_{\mathrm{f}}$, the total equivalent harmonic voltage $\boldsymbol{U}_{\mathrm{h}}$ and the total equivalent harmonic current $\boldsymbol{I}_{\mathrm{h}}$ can be represented as:

$$
\left.\begin{array}{c}
\boldsymbol{U}_{\mathrm{T}}=\boldsymbol{U}_{\mathrm{f}}+\boldsymbol{U}_{\mathrm{h}} \\
\boldsymbol{I}_{\mathrm{T}}=\boldsymbol{I}_{\mathrm{f}}+\boldsymbol{I}_{\mathrm{h}} \\
\boldsymbol{U}_{\mathrm{f}}=\left(s \boldsymbol{L}_{\mathrm{T}}+R\right) \boldsymbol{I}_{\mathrm{f}}+\boldsymbol{E}_{\mathrm{T}} \\
\boldsymbol{U}_{\mathrm{h}}=\left(s \boldsymbol{L}_{\mathrm{T}}+R\right) \boldsymbol{I}_{\mathrm{h}}
\end{array}\right\},
$$

with:

$$
\boldsymbol{U}_{\mathrm{f}}=\left[\begin{array}{l}
u_{\mathrm{a}, \mathrm{f}} \\
u_{\mathrm{b}, \mathrm{f}} \\
u_{\mathrm{c}, \mathrm{f}}
\end{array}\right], \boldsymbol{I}_{\mathrm{f}}=\left[\begin{array}{c}
i_{\mathrm{a}, \mathrm{f}} \\
i_{\mathrm{b}, \mathrm{f}} \\
i_{\mathrm{c}, \mathrm{f}}
\end{array}\right], \boldsymbol{U}_{\mathrm{h}}=\left[\begin{array}{l}
u_{\mathrm{a}, \mathrm{h}} \\
u_{\mathrm{b}, \mathrm{h}} \\
u_{\mathrm{c}, \mathrm{h}}
\end{array}\right], \boldsymbol{I}_{\mathrm{f}}=\left[\begin{array}{c}
i_{\mathrm{a}, \mathrm{h}} \\
i_{\mathrm{b}, \mathrm{h}} \\
i_{\mathrm{c}, \mathrm{h}}
\end{array}\right] \text {. }
$$


According to (6), by using Laplace formula, neglecting the initial conditions, $\boldsymbol{I}_{\mathrm{h}}$ can be represented as:

$$
\boldsymbol{I}_{\mathrm{h}}=\boldsymbol{B}(s) \boldsymbol{U}_{\mathrm{h}}
$$

with:

$$
\boldsymbol{B}(s)=\left[\begin{array}{lll}
B_{1}(s) & B_{2}(s) & B_{3}(s) \\
B_{2}(s) & B_{4}(s) & B_{5}(s) \\
B_{3}(s) & B_{5}(s) & B_{6}(s)
\end{array}\right] .
$$

It can be seen that the all the elements in the matrix $\boldsymbol{B}(s)$ including $B_{1}(s), B_{2}(s), B_{3}(s), B_{4}(s), B_{5}(s), B_{6}(s)$ can be represented by $B_{l}(s)$ :

$$
B_{l}(s)=\frac{C_{1 l} s^{2}+C_{2 l} s+C_{3 l}}{C_{4 l} s^{3}+C_{5 l} s^{2}+C_{6 l} s+C_{7 l}},
$$

where $\quad l \in\{1,2,3,4,5,6\} ; C_{1 l}, C_{2 l}, C_{3 l}, C_{4 l}, C_{5 l}, C_{6 l}, C_{7 l}$ are constants for any value of $l$. Therefore, referring to the formula of $B_{l}(s)$, it can be seen that $B_{1}(s), B_{2}(s), B_{3}(s)$, $B_{4}(s), B_{5}(s), B_{6}(s)$ are low-pass filters. The relationship between the total equivalent harmonic current $i_{\mathrm{a}, \mathrm{h}}, i_{\mathrm{b}, \mathrm{h}}, i_{\mathrm{c}, \mathrm{h}}$ and the total equivalent harmonic voltage $u_{\mathrm{a}, \mathrm{h}}, u_{\mathrm{b}, \mathrm{h}}, u_{\mathrm{c}, \mathrm{h}}$ can be represented as:

$$
\left\{\begin{array}{l}
i_{\mathrm{a}, \mathrm{h}}=B_{1}(s) u_{\mathrm{a}, \mathrm{h}}+B_{2}(s) u_{\mathrm{b}, \mathrm{h}}+B_{3}(s) u_{\mathrm{c}, \mathrm{h}} \\
i_{\mathrm{b}, \mathrm{h}}=B_{2}(s) u_{\mathrm{a}, \mathrm{h}}+B_{4}(s) u_{\mathrm{b}, \mathrm{h}}+B_{5}(s) u_{\mathrm{c}, \mathrm{h} .} \\
i_{\mathrm{c}, \mathrm{h}}=B_{3}(s) u_{\mathrm{a}, \mathrm{h}}+B_{5}(s) u_{\mathrm{b}, \mathrm{h}}+B_{6}(s) u_{\mathrm{c}, \mathrm{h}}
\end{array}\right.
$$

According to (8), the total equivalent harmonic currents $i_{\mathrm{a}, \mathrm{h}}$, $i_{\mathrm{b}, \mathrm{h}}, i_{\mathrm{c}, \mathrm{h}}$ are considered to be generated by the total equivalent harmonic voltages $u_{\mathrm{a}, \mathrm{h}}, u_{\mathrm{b}, \mathrm{h}}, u_{\mathrm{c}, \mathrm{h}}$ through lowpass filters (i.e. the resistance-inductance network $B_{l}(s)$ ). The cancellation of phase voltage harmonic components may result in the cancellation of phase current harmonic components. Section IV shows that the major torque ripple is caused by the total equivalent harmonic currents. Thus, the working principle of the proposed torque ripple reduction method is based on the cancellation of total equivalent harmonic voltage harmonic voltages. Considering the low pass filter effect of the relationship between total equivalent harmonic voltage and current and the undesired effect of low order harmonics in electric machine systems, the lower order harmonic voltage is of first importance to be eliminated.

\section{Mathematical Model of Modular PWM CONVERTERS}

For double-edge naturally sampled pulse width modulation, the complete harmonic components can be solved by using double flourier integral analysis method [15], and the phase leg voltage $\mathrm{V}_{\text {phase }}$ can be represented by:

with

$$
\begin{gathered}
u_{\text {phase }}(t)=\frac{V_{\mathrm{dc}}}{2} M \cos (y) \\
\sum_{m=1}^{\infty} \sum_{n=-\infty}^{n=\infty} A_{m n} \cos \left(m x_{p}+n y\right),
\end{gathered}
$$

$$
\begin{gathered}
A_{m n}=\frac{2 V_{\mathrm{dc}}}{m \pi} J_{n}\left(m \frac{\pi}{2} M\right) \sin \left((m+n) \frac{\pi}{2}\right), \\
x_{p}=\omega_{\mathrm{c}} t+\theta_{\mathrm{c}, p}, \\
y=\omega_{\mathrm{o}} t+\theta_{\mathrm{o}},
\end{gathered}
$$

where $m$ is the carrier index variable and it is an integer; $n$ is the baseband index variable and it is an integer; $M$ is modulation index, $0 \leq M \leq 1 ; \omega_{0}$ is the modulating signal frequency; $\omega_{c}$ is the carrier signal frequency; $\theta_{o}$ is the phase angle of the modulating signal; $\theta_{c, p}$ is the phase angle of the carrier signal in the $p^{\text {th }}$ three-phase system. The harmonic phase leg voltage $u_{\text {phase }}$ can be represented by:

$$
u_{\text {phase } \mathrm{h}}(t)=\sum_{m=1}^{\infty} \sum_{n=-\infty}^{n=\infty} A_{m n} \cos (m x+n y) .
$$

\section{Electromagnetic Toroue CAlculation}

The electromagnetic torque of multi three-phase PMSM can be represented by:

$$
\begin{gathered}
T_{\mathrm{e}}=\frac{1}{\omega_{\mathrm{m}}} \boldsymbol{I}^{\mathrm{T}} \cdot \boldsymbol{E} \\
=\frac{1}{\omega_{\mathrm{m}}}\left[\begin{array}{lllll}
i_{\mathrm{a}_{1}} & i_{\mathrm{b}_{1}} & i_{\mathrm{c}_{1}} \ldots i_{\mathrm{a}_{N}} & i_{\mathrm{b}_{N}} & i_{\mathrm{c}_{N}}
\end{array}\right]\left[\begin{array}{c}
e_{\mathrm{a}_{1}} \\
e_{\mathrm{b}_{1}} \\
e_{\mathrm{c}_{1}} \\
\vdots \\
e_{\mathrm{a}_{N}} \\
e_{\mathrm{b}_{N}} \\
e_{\mathrm{c}_{N}}
\end{array}\right],
\end{gathered}
$$

where $\omega_{\mathrm{m}}$ is the mechanical speed of the machine. Since $\boldsymbol{E}_{p}=\boldsymbol{E}_{\mathrm{N}}$ for $p \in\{1,2, \ldots, N\},(14)$ can be rewritten as:

$$
T_{\mathrm{e}}=\frac{1}{\omega_{\mathrm{m}}}\left[\begin{array}{lll}
i_{\mathrm{a}, \mathrm{T}} & i_{\mathrm{b}, \mathrm{T}} & i_{\mathrm{c}, \mathrm{T}}
\end{array}\right]\left[\begin{array}{l}
e_{\mathrm{a}_{N}} \\
e_{\mathrm{b}_{N}} \\
e_{\mathrm{c}_{N}}
\end{array}\right] .
$$

According to (15), the electromagnetic torque ripple can be represented as:

$$
T_{\mathrm{e}, \mathrm{h}}=\frac{1}{\omega_{\mathrm{m}}}\left[\begin{array}{lll}
i_{\mathrm{a}, \mathrm{h}} & i_{\mathrm{b}, \mathrm{h}} & i_{\mathrm{c}, \mathrm{h}}
\end{array}\right]\left[\begin{array}{l}
e_{\mathrm{a}_{N}} \\
e_{\mathrm{b}_{N}} \\
e_{\mathrm{c}_{N}}
\end{array}\right] .
$$

According to (16), as only the fundamental component of the back-EMF is considered, the torque ripple is related to the total equivalent harmonic current $i_{\mathrm{a}, \mathrm{h}}, i_{\mathrm{b}, \mathrm{h}}, i_{\mathrm{c}, \mathrm{h}}$. As it has been discussed in the Section II that the cancellation of phase voltage harmonic components may result in the cancellation of current harmonic components. Therefore, the working principle of the proposed torque ripple reduction method is based on the cancellation of total equivalent harmonic voltages.

\section{Analytical and Simulation Results}

Both analytical and the numerical results are obtained in order to the validate the mathematical models in Section II, III and IV. The analytical and numerical results are carried out based on a same dual three-phase drive with its converter and machine parameters listed in Table I. Analytical results are calculated based on (4), (9) and (15). The numerical results are obtained in PLECS with fixed time step of 0.01us. Fig. 2, Fig. 3 and Fig. 4 show the phase voltage, phase current and electromagnetic torque waveforms and their corresponding FFT spectra of the dual three-phase machine in both analytical and numerical results. According to Fig. 2, Fig. 3 and Fig. 4, the analytical results match with numerical

TABLE I

CONVERTER AND MACHINE PARAMETERS

\begin{tabular}{ll}
\hline \hline Parameter & Value \\
\hline DC link voltage $\left(\mathrm{V}_{\mathrm{dc}}\right)$ & $500[\mathrm{~V}]$ \\
Switching frequency $\left(f_{\mathrm{c}}\right)$ & $20[\mathrm{kHz}]$ \\
Modulating frequency $\left(f_{\mathrm{o}}\right)$ & $1[\mathrm{kHz}]$ \\
Rated power & $160[\mathrm{kw}]$ \\
Rated current & $280[\mathrm{~A}]$ \\
Pole pair number & 3 \\
Phase resistance $(R)$ & $11.47[\mathrm{~m} \Omega]$ \\
mechanical speed $\left(\omega_{m}\right)$ & $2000[\mathrm{rpm}]$ \\
stator phase inductance & $25[\mathrm{uH}]$ \\
back-EMF coefficient $\left(K_{E}\right)$ & $0.12(\mathrm{phase}$ peak back-EMF \\
& is $248 \mathrm{~V}$ at $1000 \mathrm{~Hz})$ \\
\hline \hline
\end{tabular}



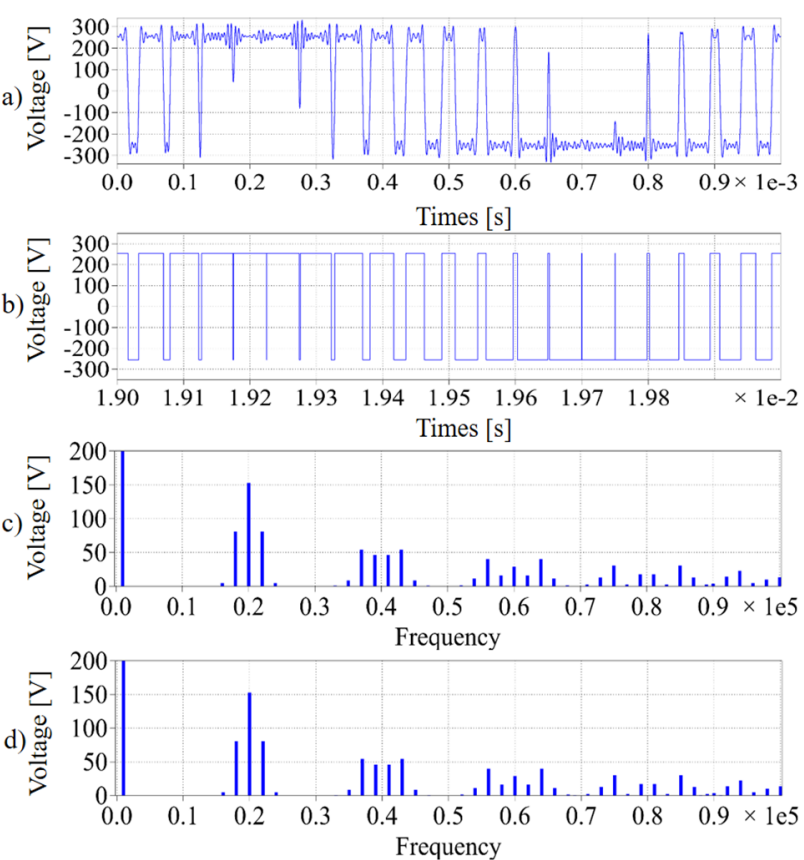

Fig. 2. a) \& b) Phase voltage waveform a) analytical result b) numerical result c) \& d) Phase voltage spectra c) analytical result d) numerical result
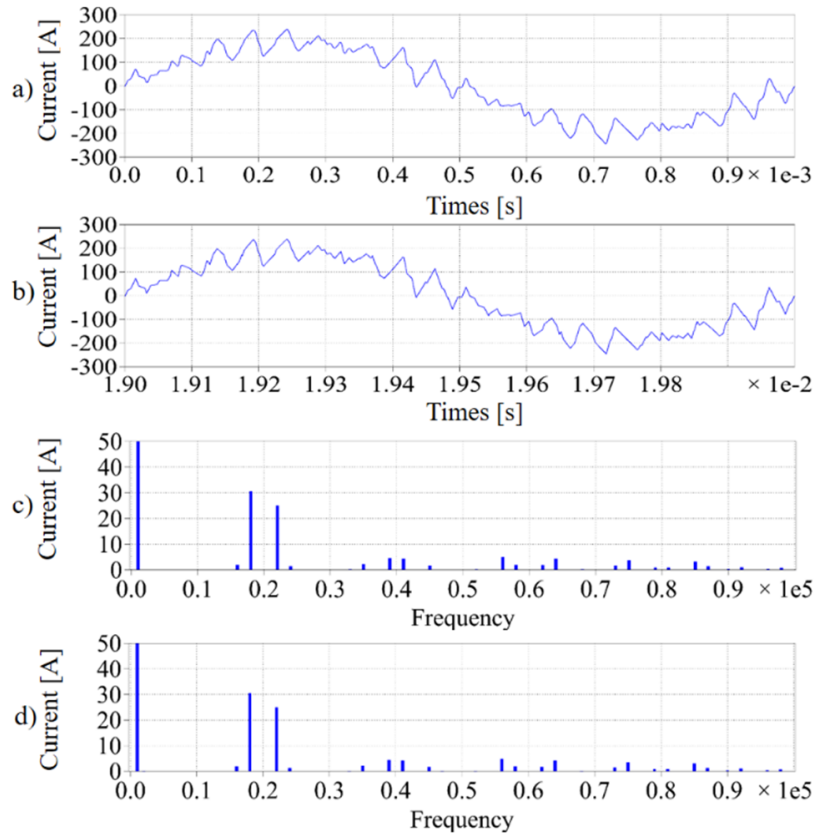

Fig. 3. a) \& b) Phase current waveform a) analytical result b) numerical result c) \& d) Phase current spectra c) analytical result d) numerical result

results in general. The phase voltage waveforms of Fig. 2a and Fig. $2 \mathrm{~b}$ are slight different, as the numerical result is obtained with infinite number of carrier signal index $\mathrm{m}$ and infinite number of modulating signal index $n$. However, the analytical result is obtained with limited number of carrier signal index $m(m=10)$ and limited number of modulating signal index $n(n=10)$ in MATLAB. This means that the higher order phase voltage harmonic components are not considered in the analytical results. The lower order phase voltage harmonic components in the analytical result match with the harmonic components in the numerical result, which is shown in Fig. 2c and Fig. 2d. There is no obvious difference between Fig. 3a (Fi. 4a) and Fig. 3b (Fig. 4b), as the phase currents (electromagnetic torque) are generated by phase
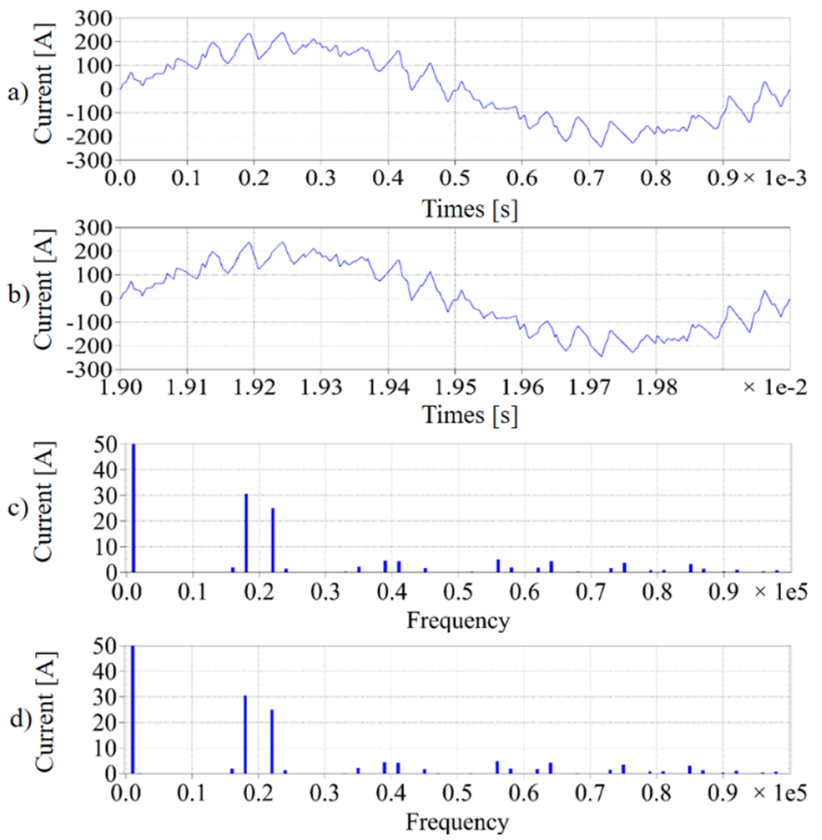

Fig. 3. a) \& b) Phase current waveform a) analytical result b) numerical result c) \& d) Phase current spectra c) analytical result d) numerical result

voltages through low pass filters, mentioned in Section II and Section IV, which indicates that the higher order phase voltage harmonic components have less effect on the phase currents and electromagnetic torque.

\section{CONCLUSION}

This work proposes a method of modelling multi threephase drive. The models of multi three-phase PMSM and voltage source PWM converter have been presented. The electromagnetic torque equations of the multi three-phase PMSM fed by modular voltage source PWM converters have been calculated. Numerical results validate the analytical models of a dual three-phase PMSM, voltage source PWM converters and electromagnetic torque equations respectively. It illustrates that the higher order phase voltage harmonic components have less effect on the phase currents and electromagnetic torque by comparing the numerical and analytical results.

\section{REFERENCE}

[1] E. Levi, R. Bojoi, F. Profumo, H. A. Toliyat, and S. Williamson, "Multiphase induction motor drives - a technology status review," IET Electr. Power Appl., vol. 1, no. 4, pp. 485-516, 2007.

[2] R. Bojoi, A. Cavagnino, A. Tenconi, and S. Vaschetto, "Control of shaft-line-embedded multiphase starter/generator for aero-engine," IEEE Trans. Ind. Electron., vol. 63, no. 1, pp. 641-652, 2016.

[3] W. Cao, B. C. Mecrow, G. J. Atkinson, J. W. Bennett, and D. J. Atkinson, "Overview of electric motor technologies used for more electric aircraft (MEA)," IEEE Trans. Ind. Electron., vol. 59, no. 9, pp. 3523-3531, 2012.

[4] I. Zoric, M. Jones, and E. Levi, "Arbitrary Power Sharing Among Three-Phase Winding Sets of Multiphase Machines," IEEE Trans. Ind. Electron., vol. 65, no. 2, pp. 1128-1139, 2017.

[5] F. Barrero and M. J. Duran, "Recent advances in the design, modeling, and control of multiphase machines - Part I," IEEE Trans. Ind. Electron., vol. 63, no. 1, pp. 449-458, 2016.

[6] F. Barrero and M. J. Duran, "Recent Advances in the Design, Modeling, and Control of Multiphase Machines - Part II," IEEE Trans. Ind. Electron., vol. 63, no. 1, pp. 459-468, 2016.

[7] A. Smirnov, N. Uzhegov, T. Sillanpaa, J. Pyrhonen, and O. Pyrhonen, "High-Speed Electrical Machine with Active Magnetic Bearing System 
Optimization," IEEE Trans. Ind. Electron., vol. 64, no. 12, pp. 98769885, 2017.

[8] P. Xu et al., "Analysis of Dual Three-Phase Permanent-Magnet Synchronous Machines with Different Angle Displacements," IEEE Trans. Ind. Electron., vol. 65, no. 3, pp. 1941-1954, 2018.

[9] Y. Ren and Z. Q. Zhu, "Enhancement of steady-state performance in direct-torque-controlled dual three-phase permanent-magnet synchronous machine drives with modified switching table," IEEE Trans. Ind. Electron., vol. 62, no. 6, pp. 3338-3350, 2015.

[10] A. S. Abdel-Khalik, A. M. Massoud, and S. Ahmed, "Effect of DCLink Voltage Limitation on Postfault Steady-State Performance of Asymmetrical Six-Phase Induction Machines," IEEE Trans. Ind. Electron., vol. 65, no. 9, pp. 6890-6900, 2018.

[11] P. Záskalický, "Complex Fourier series mathematical model of a fivephase VSI with PWM output voltage control," ELEKTRO 2016 - 11th Int. Conf. Proc., pp. 243-246, 2016.

[12] P. Záskalický and B. Dobrucký, "Analytical method of a torque ripple calculation for two-phase im supplied by three-leg SPWM inverter," 2014 Int. Symp. Power Electron. Electr. Drives, Autom. Motion, SPEEDAM 2014, pp. 731-736, 2014.

[13] P. Záskalický, “Analytical Method of a Torque Ripple Calculation for Two-Phase IM Supplied by Three-Leg SPWM Inverter,” 2014, pp. 731-736.

[14] C. Gu, Z. Zheng, L. Xu, K. Wang, and Y. Li, "Modeling and Control of a Multiport Power Electronic Transformer (PET) for Electric Traction Applications," IEEE Trans. Power Electron., vol. 31, no. 2, pp. 915-927, 2016.

[15] D. G. Holmes and T. A. Lipo, Pulse Width Modulation for Power Converters: Principles and Practice. Hoboken, NJ, USA: Wiley, 2003. 